\title{
Biosynthesis and Metabolism of NAD in Lemna paucicostata 151
}

\author{
Hiroshi Taguchi, ${ }^{\dagger}$ Hiroshi Nishitani, Katsuzumi Okumura, \\ Yoshihide SHIMABayashi and Kazuo IwaI* \\ Laboratory of Biological Chemistry, Faculty of Bioresources, \\ Mie University, Tsu, Mie 514, Japan \\ * Faculty of Home Economics, Kobe Women's University, \\ Suma-ku, Kobe 654, Japan
}

Received December 1, 1988

\begin{abstract}
We have already reported that $\mathrm{NiA}$ and related compounds had plant-growth-promoting and flower-inducing activities in duckweed, Lemna paucicostata 151 . These effects may be concerned with the biosynthesis and metabolism of NAD. So, for the first step, the various enzyme activities related to them were investigated in this study to obtain some fundamental information on the action mechanism of these compounds and metabolites. Extremely high enzyme activity of nicotinamidase and very high enzyme activity of NAD glycohydrolase were found. The enzyme activities of nicotinate phosphoribosyltransferase, quinolinate phosphoribosyltransferase, and nicotinate methyltransferase were easily detected. In contrast, nicotinamide phosphoribosyltransferase and ADP-ribosyltransferase activities were very low and nicotinamide methyltransferase activity was not detectable. NiA and NAm administered to the plant were rapidly incorporated into NAD and metabolized to several compounds. Postulation of the action mechanism is discussed.
\end{abstract}

$\mathrm{NiA}$ and its related compounds have special physiological fuctions other than vitamin activity for various plants. For example, TRG has been known as a plant mitotic cycle hormone which promotes cell arrest at the G2 stage in peas, ${ }^{1)}$ and NAm was isolated as a plant growth regulator from rice. ${ }^{2)}$ Recently flower-inducing substances have been investigated with Lemnaceae. As the results, benzoic acid and its derivatives, ${ }^{3)} \mathrm{NiA},{ }^{4)} \mathrm{NAm}$, and pipecolic acid $^{5)}$ were proved to be flowerinducing substances.

We have studied the effects of pyridine and pyrazine carboxylic acids derivatives on the growth, floral induction, and the contents of niacin and NAD in Lemna paucicostata 151.6) Among them, cinchomeronic acid (pyridine3,4-dicarboxylic acid) and TRG promoted the plant growth most strongly. Picolinic acid was the strongest inhibitior to the plant growth. We also found that NAm, NiA, etc. had flower-inducing activity. Although the action mechanisms of these compounds are not clear at present, the effects may be concerned with the biosynthesis and metabolism of NAD.

For the first step to obtain various information on the action mechanism of these compounds and their metabolites on plant growth regulation, we examined the enzyme activities related to the biosynthesis and metabolism of NAD, including the metabolism of NiA and NAm, in L. paucicostata 151.

\section{Materials and Methods}

Materials. L. paucicostata 151 was cultured aseptically in $1 / 2$ strength Hutner's medium ${ }^{7 /}$ with $1 \%$ sucrose under continuous illumination (about 4,000 lux) at $25^{\circ} \mathrm{C}$. Details

To whom correspondence should be addressed.

Abbreviations: NiA, nicotinic acid; NAm, nicotinamide; TRG, trigonelline ( $N$-methylnicotinic acid); QA, quinolinic acid; NMN, nicotinamide mononucleotide; NaMN, nicotinic acid mononucleotide; SAM, S-adenosyl-Lmethionine; PRPP, 5-phosphoribosyl-1-pyrophosphate; HEPES, $N$-(2-hydroxyethyl)-piperazine- $N^{\prime}$-2-ethanesulfonic acid; MNA, $N^{1}$-methylnicotinamide; $\mathrm{NaAD}$, nicotinic acid adenine dinucleotide. 
of the methods were described in our previous paper. ${ }^{6}$ Reagents were purchased as follows: $\left[7-{ }^{14} \mathrm{C}\right] \mathrm{NiA}$ $(56 \mathrm{mCi} / \mathrm{mmol}),\left[7^{14} \mathrm{C}\right] \mathrm{NAm}(56 \mathrm{mCi} / \mathrm{mmol})$, [carbonyl$\left.{ }^{14} \mathrm{C}\right] \mathrm{NAD}(44 \mathrm{mCi} / \mathrm{mmol})$ and [U-adenine- $\left.{ }^{14} \mathrm{C}\right] \mathrm{NAD}$ (296 mCi/mmol) from Amersham, England; [2,3,7,8${ }^{14} \mathrm{ClQA} \quad(0.267 \mathrm{mCi} / \mathrm{mmol})$ from the Daiichi Pure Chemicals Co., Ltd., Tokyo (specially prepared for us); NAD and ATP from the Kohjin Co., Ltd., Tokyo; NMN, NaMN, and SAM from Sigma Chemical Co., U.S.A.; PRPP from the Kyowa Hakko Co., Ltd., Tokyo; TRG from Tokyo Kasei Kogyo Co., Ltd., Tokyo; Dowex $1 \times 8$ (200 400 mesh) and Dowex $50 \mathrm{~W} \times 8(100 \sim 200 \mathrm{mesh})$ from the Dow Chemicals Co., U.S.A.; other reagents (guaranteed grade) from Nacalai Tesque, Inc., Kyoto.

Preparation of the cell-free extract from L. paucicostata 151. L. paucicostata 151 was cultured for 7 days in the control medium as mentioned above. These plant bodies $(10 \mathrm{~g}$, weight) were homogenized with $20 \mathrm{ml}$ of $100 \mathrm{~mm}$ HEPES buffer, $\mathrm{pH} 7.0$, containing various enzyme stabilizers ( $30 \mathrm{~mm}$ L-ascorbic acid, $10 \mathrm{~mm} 2$-mercaptoethanol, $1 \mathrm{~mm}$ EDTA, and $10 \mathrm{mg} / \mathrm{ml}$ bovine serum albumin), ${ }^{8)} 10 \mathrm{~g}$ of sea sand, and $5 \mathrm{~g}$ of polyvinylpyrrolidone in a mortar at $0^{\circ} \mathrm{C}$. The homogenate was centrifuged at $10,000 \times g$ for $10 \mathrm{~min}$ at $0 \sim 4^{\circ} \mathrm{C}$. The supernatant solution was used as enzyme sources for various enzymic reactions mentioned below without further purification. For ADPribosyltransferase activity measurement, the homogenate before centrifugation was used as an enzyme source.

Protein assay. Protein was measured by using a Bio-Rad protein assay kit with gamma globulin as a standard protein.

Enzyme assay. Nicotinate phosphoribosyltransferase (EC 2.4.2.11), nicotinamide phosphoribosyltransferase (EC 2.4.2.12), and quinolinate phosphoribosyltransferase (EC 2.4.2.19) activities were assayed by the methods of Hayakawa et al., ${ }^{9}$ Dietrich et al., ${ }^{10}$ and Iwai \& Taguchi, ${ }^{11}$ respectively. Nicotinate methyltransferase (EC 2.1.1.7) ${ }^{12}$ nicotinamide methyltransferase (EC 2.1.1.1), ${ }^{13)}$ nicotinamidase (EC 3.5.1.19), ${ }^{14)}$ NAD glycohydrolase (EC 3.2.2.5), ${ }^{15)}$ and ADP-ribosyltransferase (EC 2.4.2.30) ${ }^{161}$ activities were assayed by the methods described in each reference with slight modifications. All of these enzymic reactions were done at $30^{\circ} \mathrm{C}$ and the linearity of each reaction was checked during $3 \mathrm{hr}$ of incubation by radioassay.

Lemna assay. The assay methods of growth and flowering of the plant were described in our previous paper. ${ }^{6)}$

Extraction of labeled compounds from $L$. paucicostata 151 after administration of labeled nicotinic acid and nicotinamide. L. paucicostata 151 cultured aseptically in 1/10 strength $\mathrm{M}$ medium ${ }^{17}$ containing $\left[7^{14} \mathrm{C}\right] \mathrm{NiA}$ or $[7-$ $\left.{ }^{14} \mathrm{C}\right] \mathrm{NAm}$ (final concentration was adjusted with non- labeled NiA or NAm, so the final specific activity of the labeled compound was different in each case) was collected by filtration and washed several times with distilled water. This sample was homogenized with $1 \mathrm{ml}$ of $100 \mathrm{~mm}$ HEPES buffer, pH 7.0, in a mortar. The whole homogenate was transferred to an Eppendorf centrifuge tube (capacity, $1.5 \mathrm{ml}$ ) and heated in boiling water for $1 \mathrm{~min}$ After cooling, it was centrifuged at $9,000 \times g$ for $10 \mathrm{~min}$. The supernatant was used for fractionation and identification of niacin compounds.

Fractionation of labeled compounds in the extract from $L$. paucicostata 151. The extract was put on a Dowex $1 \times 8$ formate column $(10 \times 30 \mathrm{~mm})$ and washed with water. Then the compounds were eluted with $0.1 \mathrm{~N}$ and $5 \mathrm{~N}$ formic acid. The radioactivity of each fraction was counted by using a liquid scintillation counter, Beckman model 1801 , after mixing $0.5 \mathrm{ml}$ of the sample with $5 \mathrm{ml}$ of a water miscible scintillator (Univergel II).

Identification of labeled compounds in the extract. ${ }^{13}$ The extract $(0.1 \mathrm{ml})$ was developed on filter paper (Advantec Toyo No. 50) with three different solvent systems of $75 \%$ 2-propanol, $1 \mathrm{~m}$ ammonium acetate-95\% ethanol $(3: 7$, $\mathrm{v} / \mathrm{v}, \quad \mathrm{pH} \quad 5.0)$ and isobutyric acid-ammonia-water $(66: 1.7: 33, v / v / v)$ for $18 \sim 24 \mathrm{hr}$ at room temperature. Authentic NiA, NAm, NAD, NMN, NaMN, and TRG were chromatographed at the same time. Ultraviolet absorbing spots were detected with ultraviolet light. Then each lane on this paper was cut into small pieces (width, $2 \mathrm{~cm}$; length, $5 \mathrm{~mm}$ ). The radioactivity of each fragment was counted with a liquid scintillation counter, Beckman model 1801 , in $10 \mathrm{ml}$ of scintillation fluid which contained $4 \mathrm{~g}$ of 2,5-diphenyloxazole and $0.1 \mathrm{~g}$ of 1,4-bis[2(5phenyloxazoyl)]benzene per liter of toluene. The data from the liquid scintillation counter were processed and diagrammed automatically with an on-line microcomputer via an RS-232C interface as described before ${ }^{8)}$ Niacin activity of the each fragment obtained from the same experiments without radioactive compounds was assayed by a microbiological assay method with Lactobacillus plantarum ATCC $8014 .^{18 \text { ) }}$

All data shown in this paper are average values obtained from at least two separate experiments in duplicate.

\section{Results and Discussion}

Enzyme activities related to the biosynthesis and metabolism of NAD in L. paucicostata 151

Results are summarized in Table I. An extremely high enzyme activity of nicotinamidase and very high activity of NAD glycohydrolase were found. The enzyme activities of nicotinate phosphoribosyltransferase, quinolinate phosphoribosyltransferase, and nico- 
Table I. ENzyme Activities Related to the BIOSYNTHESIS AND METABOLISM OF NAD FOUND IN THE CEll-FreE EXTRACT From Lemna paucicostata 151 MEASURED BY RadioAsSAY METHODS

\begin{tabular}{lc}
\hline Enzyme & $\begin{array}{c}\text { Specific } \\
\text { activity } \\
\text { (pmol/mg/hr) }\end{array}$ \\
\hline Quinolinate phosphoribosyltransferase & 176 \\
Nicotinate phosphoribosyltransferase & 233 \\
Nicotinate methyltransferase & 428 \\
Nicotinamidase & 31,252 \\
Nicotinamide methyltransferase & Not detectable \\
Nicotinamide phosphoribosyltransferase & 10 \\
NAD glycohydrolase & 8,457 \\
ADP-ribosyltransferase (in homogenate) & $13^{b}$ \\
\hline
\end{tabular}

a The amount of protein for calculating this value was solely due to the protein extracted from the plant $(2.32 \mathrm{mg} / \mathrm{ml})$ and not including the BSA which was previously added in the extraction medium as an enzyme stabilizer.

$b$ Enzyme activity in the plant homogenate before preparing the cell-free extract was measured, because this enzyme has been known as to be localized in nuclei. In fact, the enzyme activity could not be detected in the cell-free extract from Lemna paucicostata 151. For the calculation of specific activity, the amount of extractable protein from the homogenate was used. The same amount of original intact cells was used in each enzyme activity measurement independent of whether the cell-free extract was used or not.

tinate methyltransferase were easily detected. Nicotinamide phosphoribosyltransferase and ADP-ribosyltransferase activities were very low and nicotinamide methyltransferase activity was not detected. From these results, the postulations mentioned below could be proposed in L. paucicostata 151 . In the salvage pathway, NAD may be synthesized through the "Nicotinic acid Pathway"; from NiA to NAD via $\mathrm{NaMN}$ and $\mathrm{NaAD}$ as shown in Fig. 1. NAm was liberated from NAD due to the high enzyme activity of NAD glycohydrolase. NAm may be rapidly converted into $\mathrm{NiA}$ by nicotinamidase and then entered in the "Nicotinic acid Pathway". Judging from both the extremely high activity of nicotinamidase and the very low activity of nicotinamide phosphoribosyltransferase, NAm scarcely en-
Table II. Dowex $1 \times 8$ Formate Colum Chromatographic Fractionation of LABELED COMPOUNDS IN THE EXTRACT FROM Lemna paucicostata 151 GRowN IN THE "M" MEDIUM CONTAINING $\left[{ }^{14} \mathrm{C}\right]$ NicotiniC ACID

\begin{tabular}{crrr}
\hline Concentration of & \multicolumn{3}{c}{ Amount in the fraction of ${ }^{a}$} \\
\cline { 2 - 4 } $\begin{array}{c}\text { nicotinic acid in } \\
\text { the medium }(\mu \mathrm{M})\end{array}$ & Water & $\begin{array}{c}0.1 \mathrm{~N} \\
\text { Formic acid }\end{array}$ & $\begin{array}{c}5 \mathrm{~N} \\
\text { Formic acid }\end{array}$ \\
\hline 1 & 1.54 & 0.18 & 0.04 \\
100 & 57.91 & 20.47 & 10.37 \\
\hline
\end{tabular}

" Amount is expressed as nicotinic acid equivalent (nmol). Details are in the text.

ters in the "Nicotinamide Pathway". TRG promoted the growth of $L$. paucicostata 151 greatly, but it did not induce flowering. ${ }^{6)}$ Nicotinate methyltransferase may be an important enzyme for the plant growth and flowering. TRG is biosynthesized from NiA and $\mathrm{SAM}^{12)}$ by this enzyme reaction.

\section{Uptake and metabolism of nicotinic acid}

At $1 \mu \mathrm{M}$ of $\mathrm{NiA}$ added in the medium, the floral induction of L. paucicostata 151 was not detected, but at $100 \mu \mathrm{M}$ it was detectable. ${ }^{6}$ Fractionation of the extract from L. paucicostata 151 cultured with $\left[{ }^{14} \mathrm{C}\right] \mathrm{NiA}$ at $1 \mu \mathrm{M}$ or $100 \mu \mathrm{M}$ is shown in Table II. Radioactivities were detected not only in the $0.1 \mathrm{~N}$ formic acid fraction in which NiA is eluted but also in the water fraction and $5 \mathrm{~N}$ formic acid fraction. The amount detected in the water fraction was up to 65 to $88 \%$ of the total radioactivity recovered. Among NiA-related compounds, TRG and NAm were eluted in this water fraction, so added NiA may be converted into these compounds in $L$. paucicostata 151. A representative paper chromatogram of metabolites in L. paucicostata 151 after culturing with $\mathrm{NiA}$ at $1 \mu \mathrm{M}$ or $100 \mu \mathrm{m}$, with a solvent system of 75\% 2-propanol, are shown in Fig. 2. Similar results (data not shown) were obtained when the extract was developed with the other two solvent systems described in Materials and Methods. According to the empirical fact in this field of research, the ordinary metabolites 


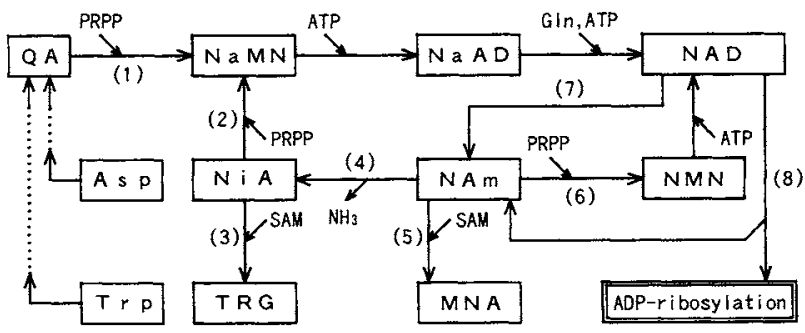

Fig. 1. Outlined Pathways of the Biosynthesis and Metabolism of NAD.

Enzymes involved in these pathways and assayed in this study were: (1) Quinolinate phosphoribosyltransferase (EC 2.4.2.19); (2) Nicotinate phosphoribosyltransferase (EC 2.4.2.11); (3) Nicotinate methyltransferase (EC 2.1.1.7); (4) Nicotinamidase (EC 3.5.1.19); (5) Nicotinamide methyltransferase (EC 2.1.1.1); (6) Nicotinamide phosphoribosyltransferase (EC 2.4.2.12); (7) NAD glycohydrolase (EC 3.2.2.5); (8) ADP-ribosyltransferase (EC 2.4.2.30).

Biosynthetic pathways of NAD,
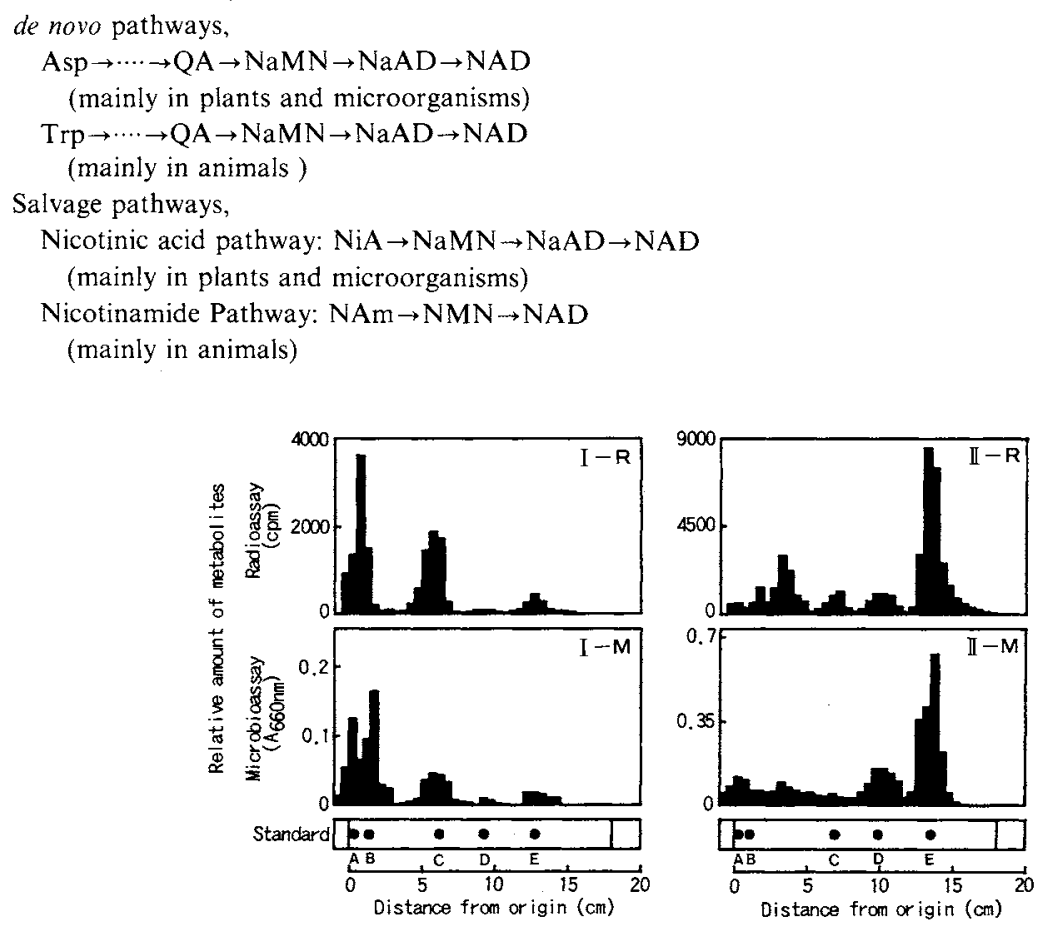

Fig. 2. Paper Chromatogram of the Extract from Lemna paucicostata 151 Cultured with Nicotinic Acid, Detected by Radioassay and Microbioassay Methods.

Nicotinic acid concentrations in the culture medium at the start were $1 \mu \mathrm{M}$ (left, I) and $100 \mu \mathrm{M}$ (right, II). Specific activities of nicotinic acid were $56 \mathrm{mCi} / \mathrm{mmol}(\mathrm{I}-\mathrm{R})$ and $2.96 \mathrm{mCi} / \mathrm{mmol}$ (II-R). Results of microbioassay for niacin activity measurement are represented in I-M and II-M. Volume of the extract developed on paper was $100 \mu$ l each and the solvent system used was 75\% 2-propanol.

Standard compounds were: A, NAD; B, nicotinic acid mononucleotide and nicotinamide mononucleotide; $\mathrm{C}$, trigonelline; $\mathrm{D}$, nicotinic acid; $\mathrm{E}$, nicotinamide. Details are in the text.

of labeled NiA and NAm can be easily identified with these high sensitive methods as adopted in this study, that is, the combination of paper partition chromatography (ra- dioassay), ion exchange column chromatography (radioassay), and microbioassay of niacin activity with $L$. plantarum ATCC 8014 (radioactive compounds are not required). In 
the extract from $L$. paucicostata 151 cultured with $\left[{ }^{14} \mathrm{C}\right] \mathrm{NiA}$ at $1 \mu \mathrm{M}$, high radioactivities were detected at the same positions as authentic NAD, NaMN, NMN, and TRG, and low radioactivity was detected in the NAm fraction. At the position corresponding to $\mathrm{NiA}$, radioactivity was scarcely detectable. Almost all the NiA incorporated into L. paucicostata 151 was converted into NAD via the "Nicotinic acid Pathway" and into TRG by nicotinate methyltransferase. In the extract from L. paucicostata 151 cultured with $\left[{ }^{14} \mathrm{C}\right] \mathrm{NiA}$ at $100 \mu \mathrm{M}$, the radioactivity at the spot corresponding to NAm was extremely high. Since the direct conversion of NiA into NAm in a free form is not known in any organism until now, the large amount of NAm detected may be liberated from NAD which was biosynthesized from NiA. Besides coenzymes for redox reactions, NAD served as the substrate for ADP-ribosylation reactions. ${ }^{19)}$ Although this reaction in plants is not well known, it may be concerned with floral induction caused by NiA. Recently, the mechanism of $\mathrm{G} 2$ arrest promoted by TRG was proposed to be mediated by ADP-ribosylation reaction. ${ }^{20)}$ Large amounts of NAm remained in a free form because of the very high enzyme activity of NAD glycohydrolase, the very low enzyme activity of nicotinamide phosphoribosyltransferase, and possibly the product inhibition mechanism of nicotinamidase. ${ }^{14)}$ In addition to these, ADP-ribosylation was inhibited by NAm. ${ }^{16)}$ So, we are postulating that the floral induction may be caused by the inhibition of ADP-ribosylation with NAm. To confirm this mechanism, we need more experimental evidence. It should be noted that an unknown compound was observed between NaMN (or NMN) and TRG on the paper chromatogram. The amount of this compound was increased when $\mathrm{NiA}$ concentration was raised from $1 \mu \mathrm{M}$ to $100 \mu \mathrm{m}$ in the culture medium. This unknown compound may also be related to the floral induction. The compound had very low vitamin activity as niacin on the microbioassay with $L$. plantarum ATCC 8014. After heating this compound in
$1 \mathrm{~N}$ sulfuric acid at $120^{\circ} \mathrm{C}$ for $1 \mathrm{hr}$, the vitamin activity as niacin became much higher. It may be an ester compound with sugar. ${ }^{21)}$ Further detailed investigation on this compound is required to solve the problem.

\section{Uptake and metabolism of nicotinamide}

Floral induction was not detected at $1 \mu \mathrm{M}$ of NAm added, but at $100 \mu \mathrm{M}$ it was detectable. ${ }^{6)}$ Fractionation of the extract from $L$. paucicostata 151 cultured with NAm at $1 \mu \mathrm{M}$ or $100 \mu \mathrm{M}$ was shown in Table III, NAm was more easily incorporated into $L$. paucicostata 151 than NiA. Besides the water fraction which contained NAm, radioactivities were detected in both the $0.1 \mathrm{~N}$ and $5 \mathrm{~N}$ formic acid fractions. The radioactivity in the water fraction reached 72 to $83 \%$ of total radioactivity recovered. NAm incorporated into L. paucicostata 151 was converted into TRG, or it remained in the free form. A representative paper chromatogram of NAm metabolites in L. paucicostata 151 cultured with $\left[{ }^{14} \mathrm{C}\right] \mathrm{NAm}$ at $1 \mu \mathrm{M}$ or $100 \mu \mathrm{M}$ is shown in Fig. 3. In the extract from $L$. paucicostata 151 cultured with $\left[{ }^{14} \mathrm{C}\right] \mathrm{NAm}$ at $1 \mu \mathrm{M}$, radioactivities were detected at the authentic NAD, NaMN, NMN, TRG, and NAm developed positions. But a radioactive spot was scarcely detected at that of NiA. As the result, NAm incorporated into $L$. paucicostata 151 was partly in the free form when $\left[{ }^{14} \mathrm{C}\right] \mathrm{NAm}$ was added at $1 \mu \mathrm{M}$. It was converted into $\mathrm{NiA}$ by nicotinamidase and the $\mathrm{NiA}$ formed may

Table 1II. Dowex $1 \times 8$ Formate COLumN Chromatographic Fractionation of LABELED COMPOUNDS IN THE EXTRACT FROM Lemna paucicostata 151 GRowN In THE "M" Medium Containing $\left[{ }^{14} \mathrm{C}\right]$ NiCOTINAMIDE

\begin{tabular}{crrr} 
Concentration of & \multicolumn{3}{c}{ Amount in the fraction of ${ }^{a}$} \\
\cline { 2 - 4 } $\begin{array}{c}\text { nicotinamide in } \\
\text { the medium }(\mu \mathrm{M})\end{array}$ & Water & $\begin{array}{c}0.1 \mathrm{~N} \\
\text { Formic acid }\end{array}$ & $\begin{array}{c}5 \mathrm{~N} \\
\text { Formic acid }\end{array}$ \\
\hline 1 & 8.85 & 0.80 & 1.01 \\
100 & 154.46 & 22.61 & 36.68
\end{tabular}

"Amount is expressed as nicotinamide equivalent (nmol). Details are in the text 

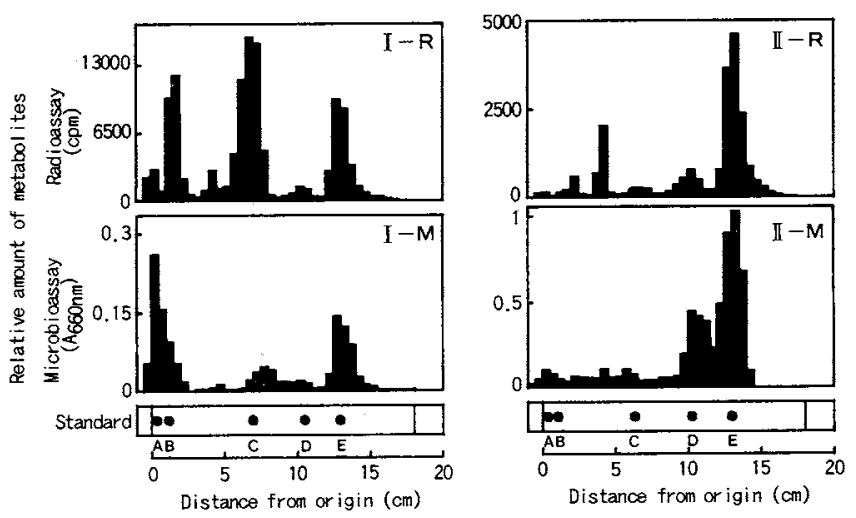

Fig. 3. Paper Chromatogram of the Extract from Lemna paucicostata 151 Cultured with Nicotinamide, Detected by Radioassay and Microbioassay Methods.

Specific activities of nicotinamide were $56 \mathrm{mCi} / \mathrm{mmol}(\mathrm{I}-\mathrm{R})$ and $0.62 \mathrm{mCi} / \mathrm{mmol}$ (II-R). Other remarks are the same as those in the legend of Fig. 2. except that nicotinamide was used in this experiment instead of nicotinic acid.

have been immediately incorporated into NAD via the "Nicotinic acid Pathway" and into TRG by nicotinate methyltransferase. In the extract from L. paucicostata 151 cultured with $\left[{ }^{14} \mathrm{C}\right] \mathrm{NAm}$ at $100 \mu \mathrm{m}$, radioactivity of the spot corresponding to NAm was extremely high. This NAm was thought to be partially liberated from NAD. Like the case of NiA, ADP-ribosylation may also be related to the floral induction. The unknown compound was observed again between NaMN (or NMN) and TRG at the same position on the paper chromatogram of $\mathrm{NiA}$ metabolites in $L$. paucicostata 151 cultured at $100 \mu \mathrm{M}$. This compound had the same nature as that of the unknown compound in Fig. 2.

Further investigation is progressing now to obtain more detailed information to solve the relationship between $\mathrm{NiA}$-related compounds and plant-growth-promoting and flowerinducing activities. These results will be published later.

\section{References}

1) D. G. Lynn, K. Nakanishi, S. L. Patt, J. L. Occolowitz, S. Almeida and L. S. Evans, J. Am. Chem. Soc., 100, 7759 (1978).

2) S. Takeuchi, Y. Kono, A. Kawarada, Y. Ota and M. Nakayama, Agric. Biol. Chem., 39, 859 (1975).

3) K. Watanabe and A. Takimoto, Plant \& Cell
Physiol., 20, 847 (1979).

4) S. Fujioka, I. Yamaguchi, N. Murofushi, N. Takahashi, S. Kaihara, A. Takimoto and C. F. Cleland, Plant \& Cell Physiol., 27, 103 (1986).

5) S. Fujioka, A. Sakurai, I. Yamaguchi, N. Murofushi, N. Takahashi, S. Kaihara and A. Takimoto, Plant \& Cell Physiol., 28, 995 (1987).

6) H. Taguchi, A. Kashimoto, H. Nishitani, Y. Shimabayashi and K. Iwai, Agric. Biol. Chem., 52, 85 (1988).

7) H. B. Posner, Plant Physiol., 44, 562 (1969).

8) H. Taguchi, M. Sakaguchi, K. Yamaki and Y. Shimabayashi, Nippon Nōgeikagaku Kaishi, 61, 183 (1987).

9) T. Hayakawa, K. Shibata and K. Iwai, Agric. Biol. Chem., 48, 445 (1984).

10) L. S. Dietrich, L. Fuller, J. L. Yero and L. Martinez, J. Biol. Chem., 241, 188 (1966).

11) K. Iwai and H. Taguchi, J. Nutr. Sci. Vitaminol., 19, 491 (1973).

12) H. Taguchi, H. Yamada, N. Ishihara, K. Okumura and Y. Shimabayashi, Vitamins (Japan), 61, 355 (1987).

13) H. Taguchi, H. Muto, K. Inamori, K. Okumura and Y. Shimabayashi, Vitamins (Japan), 62, 559 (1988).

14) H. Taguchi, K. Inamori, H. Muto, K. Okumura and Y. Shimabayashi, Vitamins (Japan), 62, 399 (1988).

15) K. Ueda, M. Fukushima, H. Okayama and $O$. Hayaishi, J. Biol. Chem., 250, 7451 (1975).

16) Y. Nishizuka, K. Ueda, K. Nakazawa and $O$. Hayaishi, J. Biol. Chem., 242, 3164 (1967).

17) W. S. Hillman, Am. J. Bot., 48, 413 (1961)

18) H. Taguchi, in "Vitamin-gaku Jikkenho II," ed. by the Vitamin Society of Japan, Tokyo Kagaku Dojin, Tokyo, 1985, pp. $356 \sim 365$. 
19) O. Hayaishi and K. Ueda, Ann. Rev. Biochem., 46, 95 (1977).

20) W. A. Tramontano, F. M. Gallousis and D. A.
Phillips, Envir. Exp. Bot., 27, 463 (1987).

21) V. Heeger, K. W. Leienbach and W. Barz, HoppeSeyler's Z. Physiol. Chem., 357, 1069 (1976). 